\title{
Results of mitral valve annuloplasty with a standard-sized posterior band: Is measuring important?
}

\author{
Morgan L. Brown, MD, ${ }^{\mathrm{a}}$ Hartzell V. Schaff, MD, ${ }^{\mathrm{a}}$ Zhuo Li, MS, ${ }^{\mathrm{b}}$ Rakesh M. Suri, MD, ${ }^{\mathrm{a}}$ \\ Richard C. Daly, MD, ${ }^{a}$ and Thomas A. Orszulak, $\mathrm{MD}^{\mathrm{a}}$
}

Objective: This study was undertaken to determine hemodynamic and clinical outcomes of annuloplasty with
a standard-sized $(63 \mathrm{~mm})$ posterior band in adult patients undergoing mitral valve repair for degenerative valve
disease.

Methods: We studied 511 patients who underwent isolated mitral valve repair for degenerative disease with a 63-mm posterior band used for annuloplasty. Operations were performed between 1994 and 2001, and average follow-up was $4.8 \pm 3.1$ years. Echocardiographic data were reviewed, with specific focus on the relationship between patient size and residual mitral regurgitation and gradient.

Results: Mean age at the time of operation was $59.3 \pm 13.5$ years, and $72 \%$ were male. Body mass index was $25.8 \pm 4.1 \mathrm{~kg} / \mathrm{m}^{2}$, and body surface area was $1.97 \pm 0.24 \mathrm{~m}^{2}$. Preoperative mean ejection fraction was $64 \% \pm$ $7 \%$, and $96 \%$ of patients had severe mitral regurgitation on preoperative echocardiography. The 30-day mortality was $0.8 \%$. At hospital discharge, the mean gradient was $4.7 \pm 3.1 \mathrm{~mm} \mathrm{Hg}$. Body surface area, body mass index, and weight were not associated with postoperative gradients or residual regurgitation at discharge. At last followup, $89 \%$ of patients had no or mild regurgitation, and the mean ejection fraction was $58 \% \pm 9 \%$. At 5 years, survival was $95 \%$ and cumulative risk of reoperation was $3 \%$.

Conclusion: A standard-sized (unmeasured) posterior annuloplasty band provided excellent intermediate results with good durability. There were neither excess gradients in larger patients nor excess regurgitation in smaller patients. Measured annuloplasty is unnecessary for most adults undergoing mitral valve repair.

There are many different techniques for mitral valve (MV) annuloplasty. Complete, rigid rings are advocated by some surgeons to remodel the annulus. Others suggest partial, flexible rings, and newer products available include 3dimensional MV annuloplasty devices. Most manufacturers recommend sizing, but sizing techniques vary widely.

At Mayo Clinic, we generally use a standard-sized $(63 \mathrm{~mm})$ flexible annuloplasty band in adult patients, regardless of MV annular dimensions or individual patient size. The technique simplifies valve repair and may lessen ischemic and operative times. Potential disadvantages, however, include the possibility of inadequate annular reduction in small patients, leading to residual mitral regurgitation (MR), and the potential for excessive annular reduction in large patients, producing some degree of MV stenosis. Our objective in this investigation was to determine hemodynamic and clinical outcomes of annuloplasty with a standard-sized $(63 \mathrm{~mm})$ posterior band and to relate outcomes to patient size.

From the Divisions of Cardiovascular Surgery ${ }^{\mathrm{a}}$ and Biostatistics, ${ }^{\mathrm{b}}$ Mayo Clinic, Rochester, Minn.

Received for publication Sept 26, 2008; revisions received Dec 11, 2008; accepted for publication Jan 4, 2009; available ahead of print April 16, 2009.

Address for reprints: Hartzell V. Schaff, MD, 200 1st St SW, Rochester, MN 55905 (E-mail: schaff@mayo.edu).

J Thorac Cardiovasc Surg 2009;138:886-91

$0022-5223 / \$ 36.00$

Copyright (C) 2009 by The American Association for Thoracic Surgery doi:10.1016/j.jtcvs.2009.01.022

\section{MATERIALS AND METHODS Patients}

After obtaining institutional review board approval, we studied patients who underwent MV repair between 1994 and 2001 with a 63$\mathrm{mm}$ posterior flexible annuloplasty band (Figure 1). We excluded patients with previous or concomitant procedures, including coronary artery bypass grafting, maze procedures, and other valvular repairs or replacements. In addition, patients were excluded if MV repair was for active or chronic endocarditis or for rheumatic or ischemic heart disease. This resulted in a study group of 511 patients who underwent isolated MV repair for degenerative MV disease with a 63-mm posterior flexible posterior annuloplasty band. Etiologies included myxomatous MV disease and leaflet prolapse from fibroelastic deficiency. All patients were contacted through survey or by telephone, and the average follow-up was $4.7 \pm$ 3.1 years. Echocardiographic data were reviewed, with specific focus on the relationship between patient size and predischarge residual MR and MV gradients.

\section{Surgical Approach}

All repairs were approached through either a median sternotomy or a right thoracotomy. Patients were placed on cardiopulmonary bypass at normothermia or mild hypothermia, and aortic cannulation and a single (2-stage) venous cannula was used in most patients. MV repair techniques included (isolated or combination) posterior leaflet resection (mainly triangular) in 361 patients $(71 \%)$, artificial chordal insertion in $92(18 \%)$, leaflet plication in $86(17 \%)$, and edge-to-edge repair in $10(2 \%)$. Annuloplasty alone was performed in 62 patients (12\%) (Table 1). All patients received a standard unmeasured annuloplasty band featuring a flexible 63-mm partial ring sutured to the posterior annulus from trigone to trigone (Figure 2). Most often, 7 to 9 mattress sutures of 2-0 pledgeted polyethylene terephthalate sutures (Ethibond; Ethicon, Inc, Somerville, NJ) were used. 

Abbreviations and Acronyms
$\mathrm{BMI}=$ body mass index
$\mathrm{BSA}=$ body surface area
$\mathrm{EF}=$ ejection fraction
$\mathrm{HR}=$ hazard ratio
$\mathrm{MR}=$ mitral regurgitation
$\mathrm{MV}=$ mitral valve
$\mathrm{SAM}=$ systolic anterior motion

\section{Statistics}

All data are reported as mean $\pm \mathrm{SD}$ or as proportions and percentages as appropriate. The SAS statistical software package (version 9.1.3; SAS Institute, Inc, Cary, NC) was used for all analyses. Patient survival and cumulative risk of reoperation on the MV (reoperation on MV, censored at death or unavailability for follow-up) were calculated with the Kaplan-Meier method. Linear regression, logistic regression, or Cox proportional hazard models were created to predict discharge MV gradient, discharge MR, survival, and reoperation on the MV. Multivariate models were created with stepwise selection methods.

Patients were divided into terciles according to weight, body surface area (BSA), and body mass index (BMI). MV gradient at discharge and degree of MR were compared between groups with 1-way analysis of variance or rank sum tests as appropriate.

\section{RESULTS}

Age at the time of operation was $59.3 \pm 13.5$ years, and $72 \%$ of the patients were male. BMI was $25.8 \pm 4.1 \mathrm{~kg} /$ $\mathrm{m}^{2}$, and BSA was $1.97 \pm 0.24 \mathrm{~m}^{2}$. The smallest patient had a BMI of $15.0 \mathrm{~kg} / \mathrm{m}^{2}$, and the largest patient had a BMI of $47.8 \mathrm{~kg} / \mathrm{m}^{2}$. The preoperative mean ejection fraction (EF) was $64 \% \pm 7 \%$, and $96 \%$ of patients had severe MR on preoperative echocardiography (Table 2). All patients had degenerative MV disease.

The 30-day mortality was $0.8 \%$. Survivals at 1,5 , and 10 years were $98 \%, 95 \%$, and $86 \%$, respectively (Figure 3). Independent predictors of overall mortality included a history of congestive heart failure (hazard ratio [HR] 4.0, $P=.0003$ ), absence of normal sinus rhythm (HR 4.3, $P=.0004)$, and lung disease (HR 3.9, $P=.0017$ ). Although weight, BMI, and BSA were associated with overall survival in a univariate analysis $(P<.05)$, they were not predictive in a multivariate analysis.

At discharge, 505 echocardiograms (99\%) were available for review. Eighty-six percent of patients had no or trivial MR, $12 \%$ had mild MR, and 2\% had moderate MR. Systolic anterior motion (SAM) of the anterior leaflet of the MV was present in $4.5 \%$ of patients at hospital discharge. There was no difference in the incidence of SAM between small, medium, and large patients. Univariate predictors of mild or greater MR included a larger preoperative cardiothoracic ratio $(P=.04)$ and a higher preoperative left ventricular end-diastolic pressure $(P=.048)$. Patient weight, BMI, and BSA were not associated with residual MR. All univariate predictors had significant missing values $(>25 \%)$, and therefore no multivariate model was fitted for predischarge MR.

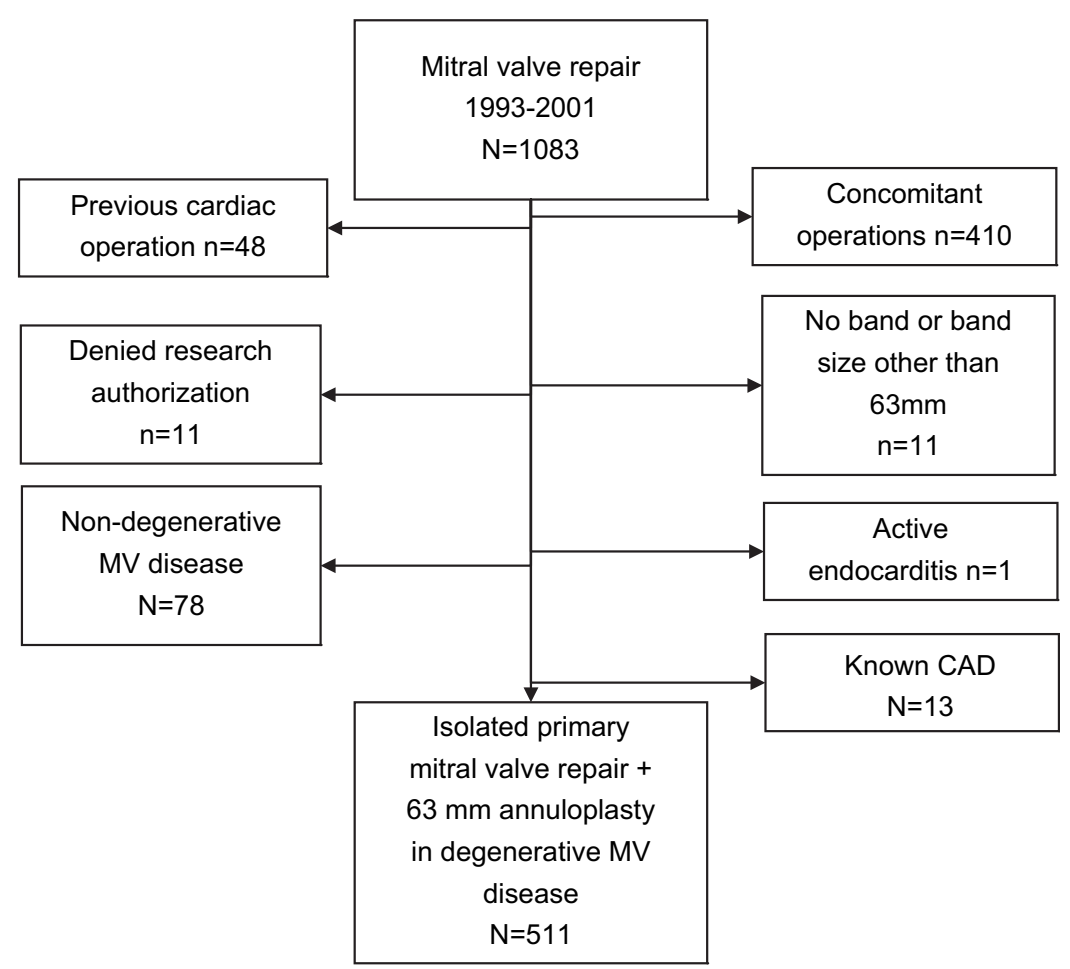

FIGURE 1. Description of patient cohort identified for this study. $M V$, Mitral valve; $C A D$, coronary artery disease. 
TABLE 1. Operative details $(n=511)$

Cardiopulmonary bypass time (min, mean $\pm \mathrm{SD})$

Crossclamp time (min, mean $\pm \mathrm{SD}$ )

Triangular or quadrangular resection (no.)

Artificial chordae (no.)

Leaflet plication (no.)

Edge to edge (no.)

Annuloplasty alone (no.)

Operative (30-d) mortality (no.)

At hospital discharge, the mean MV gradient was $3.4 \pm$ $1.4 \mathrm{~mm} \mathrm{Hg}$. Univariate predictors of a higher discharge MV gradient included a smaller cardiothoracic ratio, higher pulmonary arterial pressures, and a lower preoperative EF. On multivariate analysis, a smaller cardiothoracic ratio (estimate 0.34 per $10 \%, P=.001$ ) and a lower EF (estimate 0.193 per $10 \%, P=.044$ ) were predictive of higher postoperative gradients. There were no associations between MV gradients on predischarge echocardiograms and patient weight, BMI, or BSA.

To assess further the impact of patient size on outcome, the study cohort was divided into terciles according to preoperative weight, BSA, and BMI (Figure 4). There were no differences in either mean MV gradient or degree of MR at discharge between the smallest patients, the average-sized patients, and the largest patients. Weight, BSA, and BMI were also tested as continuous variables and were not associated with either MV gradients or MR at discharge.

At last follow-up ( $3.8 \pm 2.8$ years), 288 echocardiograms were available for review. Eighty-nine percent of patients had no or mild MR, and the average EF was $58 \% \pm 9 \%$. Some residual leaflet or chordal SAM was present in 3.5\% of patients. Cumulative risks of reoperation on the MV at 1 , 5 , and 10 years were $1 \%, 3 \%$, and $4 \%$, respectively (Figure 5). Univariate predictors of MV reoperation included in- creasing BMI (HR 1.15, $P=.017$ ) and decreasing preoperative EF (HR 1.1, $P=.047$ ). Weight and BSA were not associated with MV reoperation, and there were not enough cases of late MV repair to create a multivariate model.

\section{DISCUSSION}

In our study, we examined early and intermediate results of patients who received a standard-sized annuloplasty band as part of a primary MV repair for degenerative MV disease. We found no association between patient size (weight, BMI, or BSA) and either postrepair MV gradients or postrepair MR. Our patients who underwent MV repair also had good survival and low risk of reoperation on the MV. These data suggest that a measured annuloplasty is unnecessary for the majority of adult patients undergoing MV repair.

Methods for sizing MV annuloplasty rings or bands vary from manufacturer to manufacturer and from surgeon to surgeon. Techniques typically involve measuring the intertrigonal distance, the intercommissural distance, or the area of the anterior leaflet. ${ }^{1-3}$ At Mayo Clinic, we use a standardsized flexible annuloplasty band that is produced in a uniform size of $63 \mathrm{~mm}$ (length, not diameter). ${ }^{4}$ Pathologic studies have shown that the normal MV circumference is approximately $10 \mathrm{~cm}$, and the ratio of the length of the anterior (fibrous) portion to the posterior (muscular) annulus is $1: 2 .^{5,6}$ Thus a posterior band of approximately $6 \mathrm{~cm}$ should be sufficient to return the posterior annulus to nearly normal dimensions. In practice, this length is somewhat smaller than measured band size after the mattress sutures are secured. In general, somewhere between 7 and 9 sutures are used to attach the band and are equally spaced. The annuloplasty band we use is packaged without sizer or handle, and this may reduce cost.

By reducing the MV annulus and orifice area, annuloplasty increases the zone of coaptation of the anterior and

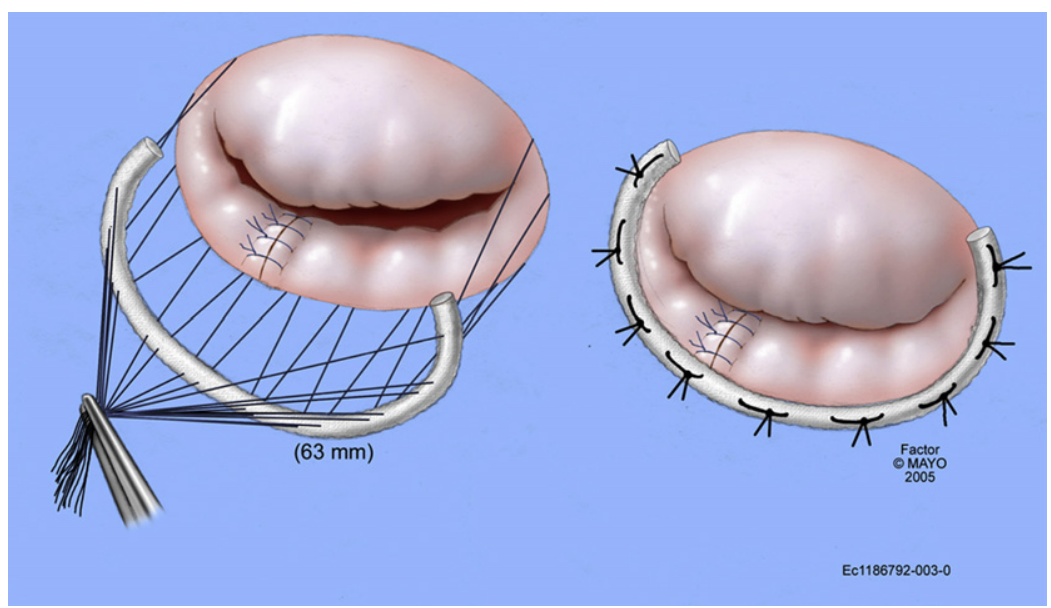

FIGURE 2. Band $(63 \mathrm{~mm})$ is sutured to posterior annulus with 7 to 9 pledgeted mattress sutures. By permission of Mayo Foundation for Medical Education and Research. All rights reserved. 
TABLE 2. Demographic data $(n=511)$

Age (y, mean \pm SD)

$59.3 \pm 13.5$

Weight $(\mathrm{kg}$, mean $\pm \mathrm{SD})$

$79.0 \pm 16.0$

Height $(\mathrm{cm}$, mean $\pm \mathrm{SD})$

Body mass index $\left(\mathrm{kg} / \mathrm{m}^{2}\right.$, mean $\left.\pm \mathrm{SD}\right)$

$174.3 \pm 9.7$

$25.8 \pm 4.1$

$1.97 \pm 0.24$

$143(28 \%)$

$239(47 \%)$

$10(2 \%)$

$222(43 \%)$

$183(36 \%)$

$55(14 \%)$

$6(1 \%)$

$456(89 \%)$

$236(46 \%)$

New York Heart Association functional class III or IV

(no.)

posterior leaflets. Also, annuloplasty reinforces posterior leaflet repair and prevents future annular dilatation. Many studies have highlighted the importance of an annuloplasty band as part of the MV repair. ${ }^{7-9}$ Alfieri and colleagues ${ }^{7}$ reported a freedom from reoperation at 4 years of $89 \% \pm 4 \%$ in patients undergoing MV repair without annuloplasty, compared with $97 \% \pm 1 \%$ in patients with annuloplasty. ${ }^{10}$ Others have found the lack of an annuloplasty band to be an independent predictor of late reoperation on the MV. ${ }^{8,9}$ There does appear to be a subset of patients who can have excellent MV repair results without annuloplasty, but these patients have yet to be well characterized. ${ }^{11,12}$

There are many annuloplasty devices available on the market today, including complete or partial rings, rigid or flexible rings, and flat or 3-dimensional types. ${ }^{13}$ Others have also advocated "'homemade"' annuloplasty bands composed of various materials, including pericardium, polytetrafluoroethylene vascular grafts, and Dacron polyester fabric grafts. ${ }^{14-17}$ Despite attempts from manufacturers to demonstrate the superiority of any one type of annuloplasty device,

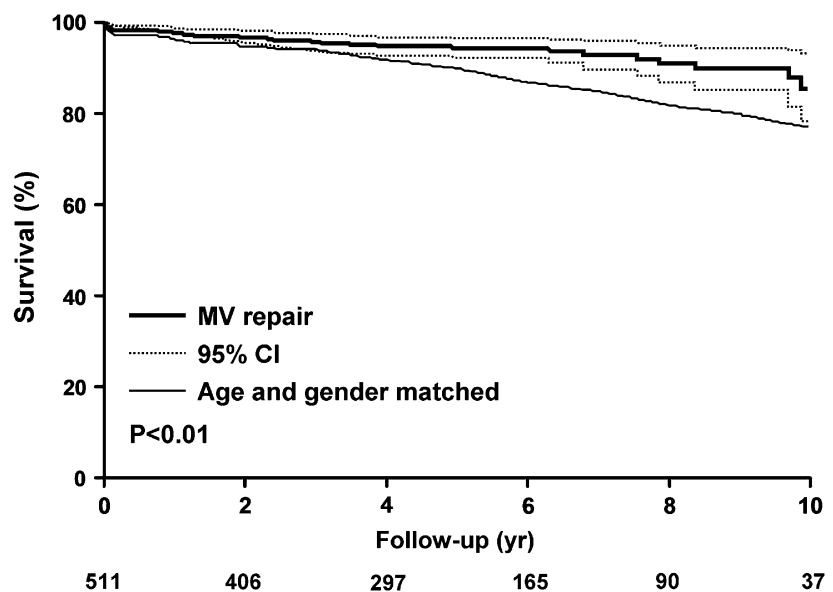

FIGURE 3. Survival after mitral valve $(M V)$ repair with standard-sized annuloplasty band. Patients with mitral valve repair are compared with ageand gender-matched population. $C I$, Confidence interval.

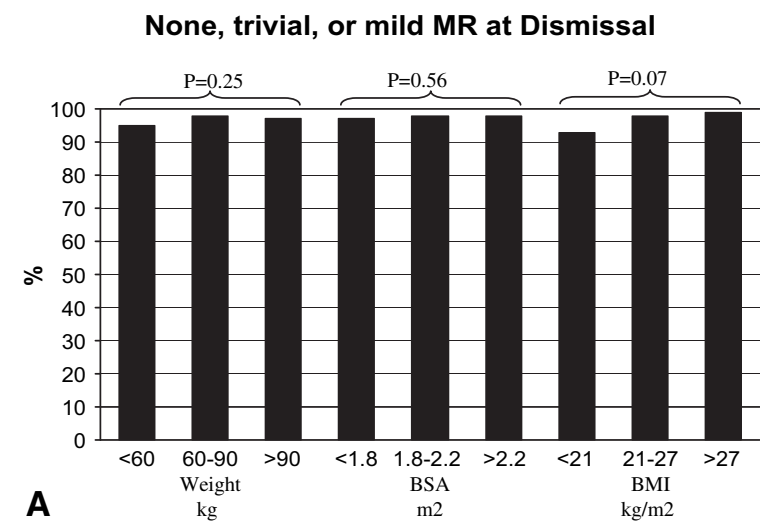

MV Gradient at Dismissal

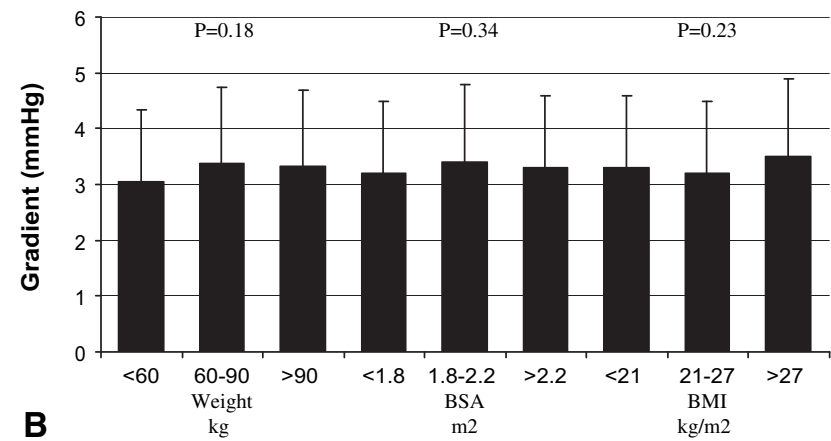

FIGURE 4. Mitral valve $(M V)$ regurgitation $(M R, \mathrm{~A})$ and mean $( \pm \mathrm{SD})$ mitral valve gradients (B) at discharge after mitral valve repair with standard-sized annuloplasty. After stratification by patient size, there were no differences among small, medium, and large patients. BSA, Body surface area; $B M I$, body mass index.

no single product has clear advantages over the others. The debate continues regarding the use of flexible versus rigid annuloplasty rings or bands in myxomatous MV disease. ${ }^{18}$ There have been many published investigations regarding types of annuloplasty devices, including at least three

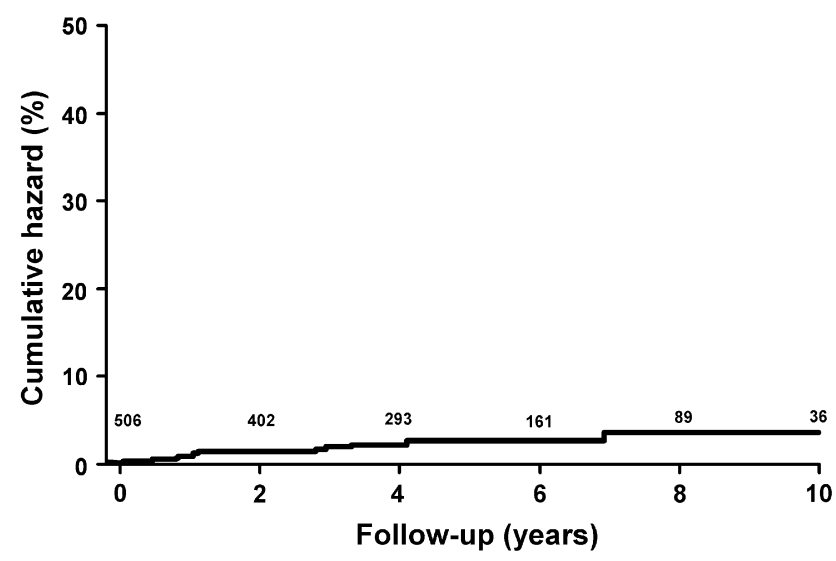

FIGURE 5. Cumulative risk of mitral valve reoperation. Patients who died or were unavailable for follow-up were censored in this analysis. 
randomized trials, but no study has definitively identified the ideal annuloplasty device. ${ }^{19-21}$

Some surgeons recommend using a complete ring because of concerns about remodeling the annulus and septal lateral dimension, as well as late anterior annular dilatation. These issues may be important with chronic ischemic MR, in which undersized annuloplasty is frequently required. ${ }^{22,23}$ Studies have shown, however, that limited isolated annular dilatation does not cause MR. ${ }^{24,25}$ In addition, our investigation demonstrates good durability and freedom from late reoperation on the MV in patients with a posterior band annuloplasty, providing evidence that a complete ring is generally not required in patients with degenerative MV disease. Indeed, risk of reoperation with this technique, approximately $0.5 \%$ per year, is similar to risk of reoperation after mechanical MV replacement for leaflet prolapse. ${ }^{9}$ A practical advantage to posterior band annuloplasty is avoidance of suture placement in the anterior portion of the annulus, which can be difficult to expose. We have reoperated on patients who have undergone repair elsewhere in which sutures anchoring the anterior portion of a complete ring pulled through valve tissue, leading to leaflet perforation and MR.

The debates about both the types and sizing of annuloplasty devices have added complexity to MV repair. We believe that by simplifying this step, surgeons can improve the chances of a competent MV repair. Although the numbers of MV repairs performed in the United States and Canada continue to grow, only approximately a third of all MV operations are repair $(23.2 \%$ in $1990,32.0 \%$ in $1999, P<.0001){ }^{26}$ These statistics include many different MV disease etiologies; nevertheless, the repair rate can be improved. The simplified approach to annuloplasty should facilitate valve repair for surgeons who have less experience or see few such cases. The unmeasured annuloplasty method is also useful in minimally invasive and robotically assisted MV repair, situations in which accurate measurement of the annulus can be difficult. ${ }^{27}$

A potential risk of an improperly undersized annuloplasty band is SAM and left ventricular outflow tract obstruction. In this study, we observed some degree of SAM in the operating room; our general management strategy has been to treat these patients with intravascular volume expansion, vasoconstriction, removal of inotropes, and $\beta$-blockade. At hospital discharge, only $4.5 \%$ of our patients had SAM, and this proportion was further reduced to $3.5 \%$ by late follow-up. In a previous study from our clinic, ${ }^{28}$ most patients had resolution of SAM with time as the left ventricle remodeled, and few patients required early or late reoperation.

Interestingly, the survival of patients in this study was better than that of an age- and gender-matched population. This is likely due to patient selection and improved medical care in patients who received a MV repair. As well, we tend to operate early in the course of MR before significant left ventricular dysfunction occurs.
In our analysis of the uniform annuloplasty band, we found no difference in either mean MV gradient or degree of MR at discharge when comparing the smallest patients, the average-sized patients, and the largest patients. These findings suggest that measurement for an annuloplasty ring or band can be eliminated in most cases without fear of residual stenosis in large patients or residual MR in small patients. The method also has excellent durability.

\section{LIMITATIONS}

In our study, approximately $2 \%$ of patients had moderate or greater MR at hospital discharge. As our knowledge of the late results of MV repair has grown, patients found to have moderate or greater MR on intraoperative echocardiography are undergoing rerepair immediately. In addition, patients who have moderate to severe MR on postoperative echocardiography will be offered rerepair during the same hospital stay.

Our echocardiographers do not routinely provide surgeons with the annular dimensions, because we do not routinely "size" the annuloplasty band. It is possible that heart size and annular size may not correlate with BSA in all cases. ${ }^{29,30} \mathrm{We}$ considered this in our analysis and therefore included weight as well as BSA and BMI.

In addition, there are probably upper and lower limits to patient size for which a standard sized annuloplasty band should be placed. As an example, a "child-sized" patient would not routinely receive a $63-\mathrm{mm}$ annuloplasty band. Our study was not designed or powered to determine the limits of patient size.

\section{CONCLUSIONS}

A standard-sized (unmeasured) posterior annuloplasty band in patients undergoing MV repair provides excellent long-term results with good durability. In our study, this method did not result in excess gradients in larger patients or residual MR in smaller patients. Measured annuloplasty is unnecessary for most adult patients undergoing repair of degenerative MV disease.

\section{References}

1. Carpentier A, Deloche A, Dauptain J, Soyer R, Blondeau P, Piwnica A, et al. A new reconstructive operation for correction of mitral and tricuspid insufficiency. J Thorac Cardiovasc Surg. 1971;61:1-13.

2. Tsakiris AG, von Bernuth G, Rastelli GC, Bourgeois MJ, Titus JL, Wood EH. Size and motion of the mitral valve annulus in anesthetized intact dogs. $J$ Appl Physiol. 1971;30:611-8.

3. Choo SJ, Olomon J, Bowles C, Lui HH, Pang D, Oury JH, et al. An in vitro study of the correlation between aortic valve diameter and mitral intertrigonal distance: a simple method to select the correct mitral annuloplasty ring size. J Heart Valve Dis. 1998;7:593-7.

4. Suri RM, Orszulak TA. Triangular resection for repair of mitral regurgitation due to degenerative disease. Oper Techniques Thorac Cardiovasc Surg. 2005;10: 194-9.

5. Olson L, Subramanian R, Ackermann D, Orszulak TA, Edwards WD. Surgical pathology of the mitral valve: a study of 712 cases spanning 21 years. Mayo Clin Proc. 1987;62:22-34. 
6. Hueb AC, Jatene FB, Moreira LFP, Pomerantzeff PM, Kallas E, De Oliveira SA. Ventricular remodeling and mitral valve modifications in dilated cardiomyopathies: new insights from anatomic study. J Cardiovasc Surg. 2002;124:1216-24.

7. Meyer MA, von Segesser LK, Hurni M, Stumpe F, Eisa K, Ruchat P. Long-term outcome after mitral valve repair: a risk factor analysis. Eur J Cardiothorac Surg. 2007;32:301-7.

8. Masiano F, Caldarola A, Blasio A, De Bonis M, La Canna G, Alfieri O. Midterm results of edge-to-edge mitral valve repair without annuloplasty. J Thorac Cardiovasc Surg. 2003;126:1987-97.

9. Suri RM, Schaff HV, Dearani JA, Sundt TM 3rd, Daly RC, Mullany CJ, et al. Survival advantage and improved durability of mitral repair for leaflet prolapse subsets in the current era. Ann Thorac Surg. 2006;82:819-26.

10. De Bonis M, Lorusso R, Lapenna E, Kassem S, De Cicco G, Torracca L, et al. Similar long-term results of mitral valve repair for anterior compared with posterior leaflet prolapse. J Thorac Cardiovasc Surg. 2006;131:364-70.

11. Barlow CW, Ali ZA, Lim E, Barlow JB, Wells FC. Modified technique for mitral repair without ring annuloplasty. Ann Thorac Surg. 2003;75:298-300.

12. Duebener LF, Wendler O, Nikoloudakis N, Georg T, Fries R, Schäfers HJ. Mitral valve repair without annuloplasty rings: results after repair of anterior leaflet versus posterior-leaflet defects using polytetrafluoroethylene sutures for chordal replacement. Eur J Cardiothorac Surg. 2000;17:206-12.

13. Jamieson WR. Advanced technologies for cardiac valvular replacement, transcatheter innovations and reconstructive surgery. Surg Technol Int. 2006;15: 149-87.

14. Bezon E, Khalifa AI, Choplain JN, Barra JA. Homemade expanded-polytetrafluoroethylene flexible mitral annuloplasty ring. Eur J Cardiothorac Surg. 2006;29:251-2.

15. Warinsirikul W, Mokarapong P, Sangchote S, Chaiyodsilp S, Tanamai S. Midterm results of mitral valve repair with homemade annuloplasty rings. Ann Thorac Surg. 1999;68:63-6.

16. Oğuş TN, Ciçek S, Işik O. Posterior mitral annuloplasty with an adjustable homemade ring. J Card Surg. 2002;17:226-8.

17. Roux D, Grinda JM, Leobon B, Prandy N, Collet JY, Fournial G, et al. Homemade mitral ring. Ann Thorac Surg. 2003;76:1315-6.

18. Chee T, Haston R, Togo A, Raja SG. Is a flexible mitral annuloplasty ring superior to a semi-rigid or rigid ring in terms of improvement in symptoms and survival? Interact Cardiovasc Thorac Surg. 2008;7:477-84.
19. David TE, Komeda M, Pollick C, Burns RJ. Mitral valve annuloplasty: the effect of the type on left ventricular function. Ann Thorac Surg. 1989;47: 524-7.

20. Chang BC, Youn YN, Ha JW, Lim SH, Hong YS, Chung N. Long-term clinical results of mitral valvuloplasty using flexible and rigid rings: a prospective and randomized study. J Thorac Cardiovasc Surg. 2007;133:995-1003.

21. Shahin GM, van der Heijden GJ, Bots ML, Cramer MJ, Jaarsma W, Gadellaa JC et al. The Carpentier-Edwards Classic and Physio mitral annuloplasty rings: a randomized trial. Heart Surg Forum. 2005;8:E389-95.

22. Tibayan FA, Rodriguez F, Langer F, Zasio MK, Bailey L, Liang D, et al. Annular remodeling in chronic ischemic mitral regurgitation: ring selection implications. Ann Thorac Surg. 2003;76:1549-54.

23. Kaji S, Nasu M, Yamamuro A, Tanabe K, Nagai K, Tani T, et al. Annular geometry in patients with chronic ischemic mitral regurgitation: three-dimensional magnetic resonance imaging study. Circulation. 2005;30(9 Suppl):I409-14.

24. Otsuji Y, Kumanohoso T, Yoshifuku S, Matsukida K, Koriyama C, Kisanuki A et al. Isolated annular dilation does not usually cause important functional mitral regurgitation: comparison between patients with lone atrial fibrillation and those with idiopathic or ischemic cardiomyopathy. J Am Coll Cardiol. 2002;39:1651-6.

25. Green GR, Dagum P, Glasson JR, Daughters GT, Bolger AF, Foppiano LE, et al. Mitral annular dilatation and papillary muscle dislocation without mitral regurgitation in sheep. Circulation. 1999;100(19 Suppl):II95-102.

26. Savage EB, Ferguson TB Jr, DiSesa VJ. Use of mitral valve repair: analysis of contemporary United States experience reported to the Society of Thoracic Surgeons National Cardiac Database. Ann Thorac Surg. 2003;75:820-5.

27. Cook RC, Nifong LW, Lashley GG, Duncan RA, Campbell JA, Law YB, et al Echocardiographic measurements alone do not provide accurate non-invasive selection of annuloplasty band size for robotic mitral valve repair. J Heart Valve Dis. 2006; 15:524-7.

28. Brown ML, Abel MD, Click RL, Morford RG, Dearani JA, Sundt TM, et al. Systolic anterior motion after mitral valve repair: is surgical intervention necessary? J Thorac Cardiovasc Surg. 2007;133:136-43.

29. Mathew RK, Gaasch WH, Guilmette NE, Schick EC, Labib SB. Anthropometric normalization of left ventricular size in chronic mitral regurgitation. Am J Cardiol. 2003;91:762-4.

30. Okamoto H, Itoh Y, Nara Y. Geometric analysis of the anterior mitral leaflet and mitral valve orifice in cadaveric hearts. Circ J. 2007;71:1794-9. 